\title{
Pilot study of sirolimus in patients with PIK3CA mutant/amplified refractory solid cancer
}

\author{
KI SUN JUNG, JEEYUN LEE, SE HOON PARK, JOON OH PARK, YOUNG SUK PARK, \\ HO YEONG LIM, WON KI KANG and SEUNG TAE KIM \\ Division of Hematology-Oncology, Department of Medicine, Samsung Medical Center, \\ Sungkyunkwan University School of Medicine, Seoul 06351, Republic of Korea
}

Received October 7, 2016; Accepted April 4, 2017

DOI: $10.3892 /$ mco.2017.1272

\begin{abstract}
In patients with refractory cancer, the effect of additional chemotherapy is very limited. Targeted agents for molecular pathways associated with cancer cell progression and survival have emerged as attractive options in several cancer types. The current pilot study assessed the efficacy and safety of sirolimus in patients with refractory cancer with PIK3CA mutation/amplification. Refractory cancer patients with PIK3CA mutation/amplification were enrolled, irrespective of tumor-types. Enrolled patients received a daily dose of $1 \mathrm{mg}$ sirolimus and one cycle defined as 28 days. An assessment of the efficacy and safety of sirolimus was performed. Overall, 4 patients were enrolled between October 2014 and April 2015. The median of 2.5 cycles of sirolimus was administered. Three patients had advanced gastric cancer and one had advanced cholangiocarcinoma. The overall response rate was $0 \%$, three patients $(75 \%)$ had stable disease following one cycle and one patient $(25 \%)$ received sirolimus for 4 cycles without disease progression. The median progression free survival was 1.9 months [95\% confidence interval (CI), 0.3-3.5 months], and the median overall survival was 3.6 months $(95 \% \mathrm{CI}$, 0.4-6.8 months). Grade 3 or greater hematologic/non-hematologic toxicity was not observed. Grade 1 nausea was reported in one patient each. There were no treatment-associated mortalities. Sirolimus had modest efficacy and a tolerable toxicity-profile in patients with refractory cancer with PIK3CA mutation/amplification.
\end{abstract}

\section{Introduction}

Molecularly targeted agents for cancer have followed the same clinical development process as cytotoxic agents, targeting

Correspondence to: Dr Seung Tae Kim, Division of Hematology-Oncology, Department of Medicine, Samsung Medical Center, Sungkyunkwan University School of Medicine, 81 Irwon-ro, Gangnam-gu, Seoul 06351, Republic of Korea

E-mail: seungtae1.kim@samsung.com

Key words: sirolimus, PIK3CA mutation, refractory cancer, survival, safety tumor location and histology (1-3). The majority of molecular alterations in tumor genetics exist across different tumor types and histologies, although the incidence varies (4). This observation challenges existing drug development strategies for molecularly targeted agents and raises the possibility of a shift towards histology-agnostic molecularly-based treatment (5). Of these targets, the phosphatidylinositide-3-kinase (PIK3CA) pathway is essential in the metabolism, proliferation and apoptosis of cells (6). Relatively common mutations of the PIK3CA associated pathway are 4 hotspots: H1047R, E542 K, E545K and phosphatase and tensin homolog (PTEN) loss (7). The phosphoinositide 3-kinase (PI3K)-v Akt murine thymoma viral oncogene homolog (AKT)-mechanistic target of rapamycin (mTOR) signaling cascade is one of the most important intracellular pathways to be frequently activated in diverse cancer types $(8,9)$. The association between the activation of the PI3K-AKT-mTOR pathway and tumorigenesis and cancer progression in numerous types of tumors is well established, and may contribute to acquire resistance to various anti-neoplastic agents $(8,10)$. Activation of the PIK3CA pathway increases the signaling of the AKT/mTOR pathway and stimulates proliferation of the cell (11-13).

mTOR inhibitors interrupts translation and expression of major proteins that regulate gene expression, cell cycle and angiogenesis (14). In vitro, these agents inhibit growth and proliferation of tumor cells including cancer of the ovary, breast, lung, prostate and kidney (15). Of the first generation mTOR inhibitors, sirolimus has been approved by the Food and Drug Administration as an agent that prevent rejection of kidney transplantation $(16,17)$. Certain previous studies compared the effects of sirolimus vs. placebo in a mouse model of colon cancer with PIK3CA mutation (17,18). A marked difference in the ratio of change from baseline volume in PET-CT was identified between sirolimus and placebo (-83.1 vs. $+96 \%$, respectively) $(18,19)$.

Although several chemotherapeutic agents have been developed, their effects on refractory cancer are limited and clinical benefits are only obtained in specific patient-subpopulations (20-22). Therefore, specific biomarkers for various patient subpopulations are required to identify the patients who would receive the most benefit from sirolimus treatment. Several previous studies have suggested that PIK3CA genomic aberrations may be strong predictors of efficacy 
of mTOR inhibitors $(11,23)$. Therefore, the advancement of targeted agents against specific pathways associated with cancer-progression are required for patients with refractory cancer. Thus, the present study assessed the efficacy and safety of sirolimus in patients with refractory cancer with PIK3CA mutation/amplification.

\section{Materials and methods}

Eligibility. The present study was an open-labeled, single arm, prospective single-center clinical trial to evaluate efficacy and safety of sirolimus in patients with refractory cancer with PIK3CA mutation/amplification. Patients were enrolled between October 2014 and April 2015 at Samsung Medical Center (Seoul, Korea). Patients were eligible if they had a histologically confirmed refractory solid cancer with PIK3CA mutation/amplification. The inclusion criteria were: An age between 18 and 75 years, $\geq 1$ measurable lesion, Eastern Cooperative Oncology Group performance status of 0-2 and a life expectancy $\geq 3$ months. Adequate hematologic function [absolute neutrophil count $(\mathrm{ANC}) \geq 1,500 \mathrm{~mm}^{3}$ (normal range, $1,500-7,500 \mathrm{~mm}^{3}$ ), platelet count $\geq 75,000 \mathrm{~mm}^{3}$ (normal range, 150,000-450,000 $\left.\mathrm{mm}^{3}\right)$ ], hepatic function [aspartate aminotransferase/alanine aminotransferase $\leq 3.0$ times the upper normal limit (UNL), bilirubin $\leq 1.5$ times the UNL], and renal function (serum creatinine $\leq 1.5$ times the UNL) were also required. Patients receiving sirolimus as a prior treatment were excluded. All patients provided written informed consent according to the guidelines provided by the institutional review board and all procedures were carried out according to guidelines from the Declaration of Helsinki. The Institutional Review Board at Samsung Medical Center approved the protocol.

Study design and objectives. PIK3CA amplification/mutation was detected by targeted deep sequencing by CancerSCAN $^{\mathrm{TM}}$ (24). Briefly, extracted genomic DNA was sheared to 150-200 bp fragments using Covaris S220 (Covaris, Woburn, MA, USA) and targeted genes were captured using a custom panel capture library (Agilent Technologies, Inc., Santa Clara, CA, USA) for $2.5 \mathrm{Mb}$ of exonic regions with an Illumina Paired-End Sequencing Library kit. DNA sequencing of 100 or 101-bp paired-end reads was performed using the Illumina HiSeq 2,500 sequencer (Illumina, Inc., San Diego, CA, USA). There is no established dose of sirolimus, although several studies reported effective oral daily doses of $0.5-10 \mathrm{mg}(25,26)$. The dose and schedule of sirolimus based was determined based on previous phase I studies $(27,28)$. Sirolimus was administered orally at a daily dose of $1 \mathrm{mg}$ continuously (28 day cycles). Treatment was continued from day 1 , and was terminated due to progression of the disease, unacceptable toxicity or the patient's request. Thereafter, the patients were followed up. Toxicity was assessed each cycle using the National Cancer Institute Common Terminology Criteria for Adverse Events, version 4.0 (29). Patients underwent radiological evaluation every 4 weeks and clinical tumor response was assessed using the Response Evaluation Criteria in Solid Tumors (RECIST version 1.1) (30).

The primary objective of this study was the progression free survival (PFS). The second objectives were evaluated overall survival (OS), overall response rate, disease control

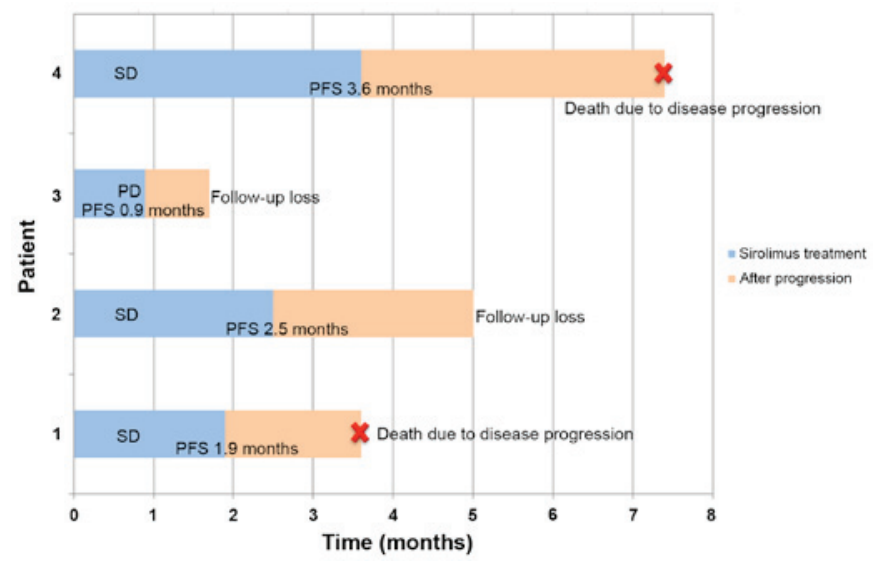

Figure 1. Clinical course of patients with PIK3CA (+) refractory cancer during the follow-up period. (no. 1) The PFS was 1.9 months. The patient succumbed to disease progression. (nos. 2 and 3) Patient no. 2 received sirolimus for 2.5 months and no. 3 received sirolimus for 0.9 months. The two patients were finally transferred to another hospital for supportive care. (no. 4) The PFS was 3.6 months. The patient succumbed to disease progression and sepsis. PFS, progression free survival; SD, stable disease; PD, progressive disease.

rate (DCR) and safety. Following an analysis of the feasibility of sirolimus for refractory cancer patients with PIK3CA mutation/amplification in this pilot study, a further phase II trial will be considered.

Statistical analysis. Patient characteristics were presented using descriptive statistics. PFS was calculated from the first day of treatment to the date on which progressive disease was first observed or on the day of the last follow-up. OS was calculated from the first day of treatment to the date of mortality or last follow-up. PFS and OS were estimated using the Kaplan-Meier method. Response rate was calculated as the ratio of the number of patients who achieved a complete response or partial response (PR) to the number of assessable patients. DCR was defined as ratio of patients achieved more than stable disease at 8 weeks. Statistical data were analyzed using SPSS version 18 (IBM Corp., Armonk, NY, USA).

\section{Results}

Patient characteristics. This study enrolled 4 patients who met the inclusion criteria. The baseline characteristics of patients are shown in Table I. The median age of the patients was 53.3 years (range, 49-61), and all the patients were male. Three patients were diagnosed with advanced gastric cancer and one patient had hilar cholangiocarcinoma. The median time from initial diagnosis was 16.0 months (range, 14.5-19.5). All patients received more than second- line chemotherapy. According to the results of next generation sequencing, one patient had an E542K mutation and the remaining patients had an $\mathrm{E} 545 \mathrm{~K}$ mutation.

Efficacy and treatment response. A median of 2.5 cycles of sirolimus was administered. There was no patient with more than a PR. Three patients had stable disease after one cycle of sirolimus. Patient no. 1 had progressive disease following one cycle of sirolimus. Patients nos. 2 and 3 experienced disease 
Table I. Baseline patient characteristics.

\begin{tabular}{|c|c|c|c|c|}
\hline Variables & Patient no. 1 & Patient no. 2 & Patient no. 3 & Patient no. 4 \\
\hline Age & 51 & 49 & 61 & 56 \\
\hline Sex & Male & Male & Male & Male \\
\hline ECOG PS & 1 & 1 & 1 & 1 \\
\hline Primary cancer & $\mathrm{AGC}$ & AGC & Hilar CCC & AGC \\
\hline Metastatic site & $\begin{array}{l}\text { Lymph node } \\
\text { Bone }\end{array}$ & $\begin{array}{l}\text { Adrenal gland } \\
\text { Peritoneal seeding }\end{array}$ & $\begin{array}{l}\text { Liver Lung } \\
\text { Peritoneal seeding } \\
\text { Pleural seeding }\end{array}$ & Liver \\
\hline \multicolumn{5}{|l|}{ Prior chemotherapy } \\
\hline 1st line & $\begin{array}{c}\text { FOLFOX + } \\
\text { Onartuzumab }\end{array}$ & FOLFIRI & CCRT with 5FU & XELOX \\
\hline $\begin{array}{l}\text { 2nd line } \\
\text { 3rd line }\end{array}$ & $\begin{array}{c}\text { Paclitaxel } \\
-\end{array}$ & $\begin{array}{c}\text { Docetaxel } \\
-\end{array}$ & $\begin{array}{l}\text { GP } \\
\text { XP }\end{array}$ & $\begin{array}{l}\text { Paclitaxel } \\
\text { FOLFIRI }\end{array}$ \\
\hline PIK3CA mutation & $\begin{array}{l}\text { E545K mutation } \\
\text { PTEN loss >90\% } \\
\text { of tumor cells }\end{array}$ & $\begin{array}{l}\text { E542K mutation } \\
\text { PTEN loss in } 100 \% \\
\text { of tumor cells }\end{array}$ & $\begin{array}{l}\text { E545K mutation } \\
\text { No PTEN loss }\end{array}$ & $\begin{array}{l}\text { E545K mutation } \\
\text { PTEN loss in } 100 \% \\
\text { of tumor cells }\end{array}$ \\
\hline
\end{tabular}

progression following the second cycle of sirolimus and patient no. 4 had disease progression following the 4 th cycle. The DCR at 8 weeks was $25 \%$. The clinical course of the 4 patients is presented in Fig. 1. The median PFS was 1.9 months [95\% confidence interval (CI); 0.3-3.5 months; Fig. 2A], and the median OS was 3.6 months (95\% CI, 0.4-6.8 months; Fig. 2B).

Safety. Dose reduction or treatment delay was not required in the enrolled patients. Grade 3 or greater hematologic/non-hematologic toxicity was not observed. Grade 1 nausea was reported in one patient. There were no treatment-associated mortalities.

\section{Discussion}

PIK3CA is a key down-stream protein kinase of the PI3K-AKT signaling pathway, and sirolimus is a novel macrolide derivative of rapamycin that inhibits mTOR, thereby preventing phosphorylation of its downstream molecules. In the present study, the anti-tumor activity of sirolimus was investigated in solid tumors with a specific genotypes concerning PIK3CA amplification/mutation. In the current study, sirolimus had modest clinical benefits and a tolerable toxicity-profile in patients with refractory cancer with PIK3CA mutation/amplification.

In the present study, 3 of 4 patients had metastatic gastric cancer. In the second-line chemotherapy setting, numerous phase III clinical trials of targeted agents for advanced gastric cancer are ongoing presently $(31,32)$. Of several studies, one phase III trial with an mTOR inhibitor was the GRANITE-1 study (33). In this previous study, the efficacy of everolimus, an oral mTOR serine/threonine kinase
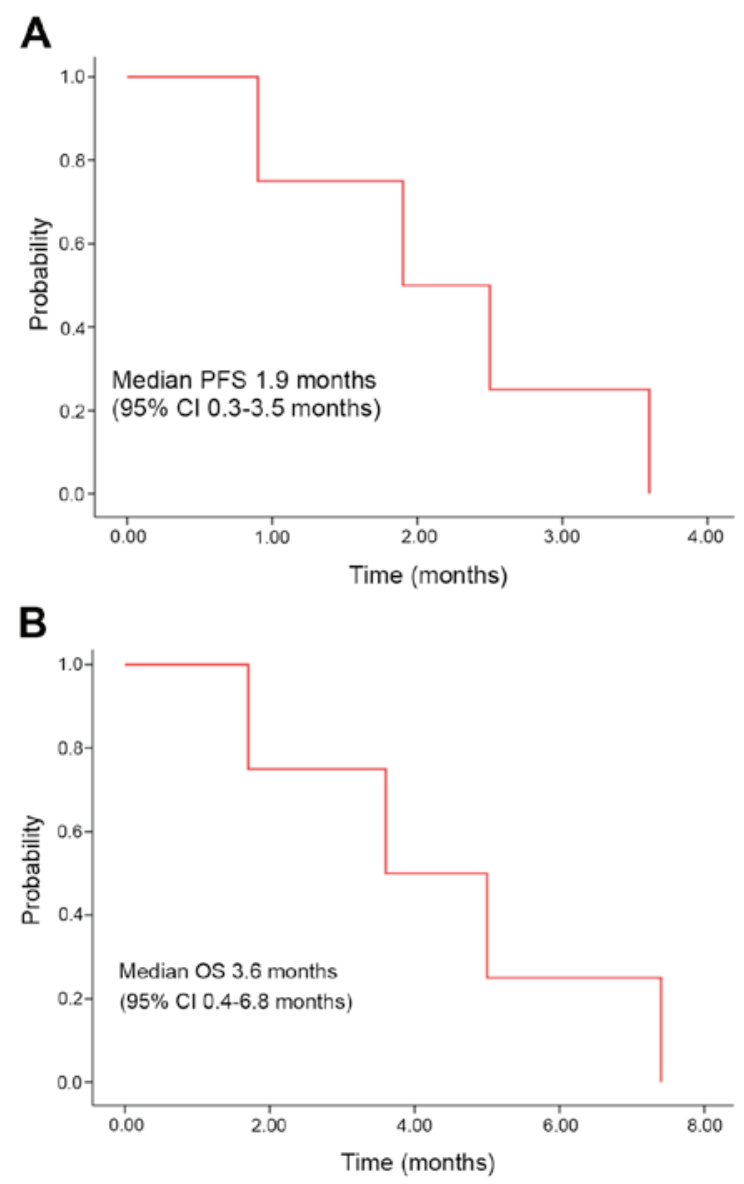

Figure 2. (A) Kaplan-Meier curve of PFS and (B) OS following the treatment of PIK3CA $(+)$ refractory cancer with sirolimus $(\mathrm{N}=4)$. PFS, progression free survival; CI, confidence interval; OS, overall survival. 
inhibitor, was compared with the efficacy of best supportive care only. The median PFS was 1.7 months with everolimus vs. 1.4 months with placebo (hazard ratio, $0.66 ; 95 \% \mathrm{CI}$, $0.56-0.78 ; \mathrm{P}<0.0001)(25)$. PFS in 3 gastric cancer patients of the current study was 1.9, 2.5 and 3.6 months. These patients received sirolimus as a third or fourth line therapy. Sirolimus may be a potential option to consider for heavily pretreated patients with gastric cancer.

There have been several studies concerning mTOR inhibitors in patients with a PIK3CA mutation (12). PIK3CA mutation has been reported in a number of cancer types, including malignancies of the colon, breast, liver and ovary (11), with the most common mutations being E545 K, E542K in exon 9 and H1047R in exon 20 (7). According to certain studies, patients with a PIK3CA mutation and/or PTEN aberrations have a greater response to mTOR inhibitors compared with patients with wild type tumors, and in particular, H1047R mutation was associated with a high response to mTOR inhibitors $(11,12)$. On the other hand, certain studies reported that PTEN loss was associated with reduced sensitivity to mTOR inhibitors due to Akt activation, limiting the effect of mTOR inhibition $(34,35)$. In the present study, the genotype of PIK3CA mutations was E545K in 3 patients and $\mathrm{E} 542 \mathrm{~K}$ in 1 patient, and there was no H1047R mutation. In addition, three gastric cancer patients revealed PTEN loss in the immunohistochemistry (IHC).

Although tumors had a PIK3CA mutation or PTEN loss, there are a number of factors that may underlie differing responses to mTOR inhibitors. Varying tumor types may have different subgroups of PIK3CA mutation and co-existing mutations (36). In colorectal cancer, PIK3CA exon 9 mutations are associated with K-ras mutation but exon 20 mutations are not associated with K-ras mutation $(37,38)$. Due to concomitant MARK mutations, these subgroups do not respond well to mTOR inhibitor therapy $(37,38)$. In another case series, patients with PIK3CA mutation combined with pS6 over expression were associated with a good response to mTOR inhibitors and long duration of disease control (39). Therefore, clinical features and co-existing mutations alongside PIK3CA mutation, dependent on the cancer type, require further investigation to elucidate the applications of mTOR inhibitors. Although the present study used biomarker-driven patient selection, PIK3CA mutation/amplification and/or PTEN loss were not sufficient for predicting the anti-tumor activity of sirolimus. Thus, a more comprehensive molecular analysis is required to fully realize the potential of personalized medicine using mTOR inhibitors including sirolimus.

In conclusion, as the present research was a pilot study, the sample size was small and the patient population was heterogeneous. Nevertheless, sirolimus had modest efficacy and a tolerable toxicity profile in patients with refractory cancer with PIK3CA mutation/amplification. These findings support the premise of further investigations. Therefore, a phase II clinical trial of sirolimus in patients with refractory cancer with PIK3CA mutation/amplification is currently being conducted.

\section{References}

1. Shaw AT, Kim DW, Nakagawa K, Seto T, Crinó L, Ahn MJ, De Pas T, Besse B, Solomon BJ, Blackhall F, et al: Crizotinib versus chemotherapy in advanced ALK-positive lung cancer. N Engl J Med 368: 2385-2394, 2013.
2. Sosman JA, Kim KB, Schuchter L, Gonzalez R, Pavlick AC, Weber JS, McArthur GA, Hutson TE, Moschos SJ, Flaherty KT, et al: Survival in BRAF V600-mutant advanced melanoma treated with vemurafenib. N Engl J Med 366: 707-714, 2012.

3. Sekulic A, Migden MR, Oro AE, Dirix L, Lewis KD, Hainsworth JD, Solomon JA, Yoo S, Arron ST, Friedlander PA, et al: Efficacy and safety of vismodegib in advanced basal-cell carcinoma. N Engl J Med 366: 2171-2179, 2012.

4. Ciriello G, Miller ML, Aksoy BA, Senbabaoglu Y, Schultz N and Sander C: Emerging landscape of oncogenic signatures across human cancers. Nat Genet 45: 1127-1133, 2013.

5. Yarden Y and Sliwkowski MX: Untangling the ErbB signalling network. Nat Rev Mol Cell Biol 2: 127-137, 2001.

6. Cantley LC: The phosphoinositide 3-kinase pathway. Science 296: 1655-1657, 2002.

7. Karakas B, Bachman KE and Park BH: Mutation of the PIK3CA oncogene in human cancers. Br J Cancer 94: 455-459, 2006.

8. Engelman JA: Targeting PI3K signalling in cancer: Opportunities, challenges and limitations. Nat Rev Cancer 9: 550-562, 2009.

9. Laplante M and Sabatini DM: mTOR signaling in growth control and disease. Cell 149: 274-293, 2012.

10. Burris HA III: Overcoming acquired resistance to anticancer therapy: Focus on the PI3K/AKT/mTOR pathway. Cancer Chemother Pharmacol 71: 829-842, 2013.

11. Janku F, Hong DS, Fu S, Piha-Paul SA, Naing A, Falchook GS, Tsimberidou AM, Stepanek VM, Moulder SL, Lee JJ, et al: Assessing PIK3CA and PTEN in early-phase trials with PI3K/AKT/mTOR inhibitors. Cell Rep 6: 377-387, 2014.

12. Janku F, Wheler JJ, Naing A, Stepanek VM, Falchook GS, Fu S, Garrido-Laguna I, Tsimberidou AM, Piha-Paul SA, Moulder SL, et al: PIK3CA mutations in advanced cancers: Characteristics and outcomes. Oncotarget 3: 1566-1575, 2012.

13. Vivanco I and Sawyers CL: The phosphatidylinositol 3-Kinase AKT pathway in human cancer. Nat Rev Cancer 2: 489-501, 2002.

14. Zaytseva YY, Valentino JD, Gulhati P and Evers BM: mTOR inhibitors in cancer therapy. Cancer Lett 319: 1-7, 2012.

15. Aoki M, Blazek E and Vogt PK: A role of the kinase mTOR in cellular transformation induced by the oncoproteins P3k and Akt. Proc Natl Acad Sci USA 98: 136-141, 2001.

16. Guba M, von Breitenbuch P, Steinbauer M, Koehl G, Flegel S, Hornung M, Bruns CJ, Zuelke C, Farkas S, Anthuber M, et al: Rapamycin inhibits primary and metastatic tumor growth by antiangiogenesis: Involvement of vascular endothelial growth factor. Nat Med 8: 128-135, 2002.

17. Dupont $\mathrm{P}$ and Warrens AN: The evolving role of sirolimus in renal transplantation. QJM 96: 401-409, 2003.

18. Leystra AA, Deming DA, Zahm CD, Farhoud M, Olson TJ, Hadac JN, Nettekoven LA, Albrecht DM, Clipson L, Sullivan R, et al: Mice expressing activated PI3K rapidly develop advanced colon cancer. Cancer Res 72: 2931-2936, 2012.

19. Deming DA, Leystra AA, Farhoud M, Nettekoven L, Clipson L, Albrecht D, Washington MK, Sullivan R, Weichert JP and Halberg RB: mTOR inhibition elicits a dramatic response in PI3K-dependent colon cancers. PLoS One 8: e60709, 2013.

20. Park HS, Lim SM, Kim S, Kim S, Kim HR, Kwack K, Lee MG, Kim JH and Moon YW: Pilot study of a next-generation sequencing-based targeted anticancer therapy in refractory solid tumors at a Korean Institution. PLoS One 11: e0154133, 2016.

21. Von Hoff DD, Stephenson JJ Jr, Rosen P, Loesch DM, Borad MJ, Anthony S, Jameson G, Brown S, Cantafio N, Richards DA, et al: Pilot study using molecular profiling of patients' tumors to find potential targets and select treatments for their refractory cancers. J Clin Oncol 28: 4877-4883, 2010.

22. Tsimberidou AM, Iskander NG, Hong DS, Wheler JJ, Falchook GS, Fu S, Piha-Paul S, Naing A, Janku F, Luthra R, et al: Personalized Medicine in a phase i clinical trials program: The MD Anderson cancer center initiative. Clin Cancer Res 18: 6373-6383, 2012.

23. PIK3CA mutations predict response to PI3K/AKT/mTOR inhibitors. Cancer Discovery 2: 205-205, 2012.

24. Kim ST, Lee J, Park SH, Park JO, Park YS, Kang WK and Lim HY: Prospective phase II trial of everolimus in PIK3CA amplification/mutation and/or PTEN loss patients with advanced solid tumors refractory to standard therapy. BMC Cancer 17: 211, 2017.

25. Rizell M, Andersson M, Cahlin C, Hafström L, Olausson M and Lindnér P: Effects of the mTOR inhibitor sirolimus in patients with hepatocellular and cholangiocellular cancer. Int J Clin Oncol 13: 66-70, 2008. 
26. Reardon DA, Quinn JA, Vredenburgh JJ, Gururangan S, Friedman AH, Desjardins A, Sathornsumetee S, Herndon JE II, Dowell JM, McLendon RE, et al: Phase 1 trial of gefitinib plus sirolimus in adults with recurrent malignant glioma. Clin Cancer Res 12: 860-868, 2006.

27. Martin-Liberal J, Gil-Martín M, Sáinz-Jaspeado M, Gonzalo N, Rigo R, Colom H, Muñoz C, Tirado OM and García del Muro X: Phase I study and preclinical efficacy evaluation of the mTOR inhibitor sirolimus plus gemcitabine in patients with advanced solid tumours. Br J Cancer 111: 858-865, 2014.

28. Desar IM, Timmer-Bonte JN, Burger DM, van der Graaf WT and van Herpen CM: A phase I dose-escalation study to evaluate safety and tolerability of sorafenib combined with sirolimus in patients with advanced solid cancer. Br J Cancer 103: 1637-1643, 2010.

29. Dueck AC, Mendoza TR, Mitchell SA, Reeve BB, Castro KM, Rogak LJ, Atkinson TM, Bennett AV, Denicoff AM, O'Mara AM, et al: Validity and reliability of the US national cancer institute's patient-reported outcomes version of the common terminology criteria for adverse Events (PRO-CTCAE). JAMA Oncol 1: 1051-1059, 2015.

30. Eisenhauer EA, Therasse P, Bogaerts J, Schwartz LH, Sargent D, Ford R, Dancey J, Arbuck S, Gwyther S, Mooney M, et al: New response evaluation criteria in solid tumours: Revised RECIST guideline (version 1.1). Eur J Cancer 45: 228-247, 2009.

31. Matsuoka $\mathrm{T}$ and Yashiro M: The role of PI3K/Akt/mTOR signaling in gastric carcinoma. Cancers 6: 1441-1463, 2014

32. Liu L, Wu N and Li J: Novel targeted agents for gastric cancer. J Hematol Oncol 5: 31, 2012

33. Ohtsu A, Ajani JA, Bai YX, Bang YJ, Chung HC, Pan HM, Sahmoud T, Shen L, Yeh KH, Chin K, et al: Everolimus for previously treated advanced gastric cancer: Results of the randomized, double-blind, phase III GRANITE-1 study. J Clin Oncol 31: 3935-3943, 2013
34. Seront E, Pinto A, Bouzin C, Bertrand L, Machiels JP and Feron O: PTEN deficiency is associated with reduced sensitivity to mTOR inhibitor in human bladder cancer through the unhampered feedback loop driving PI3K/Akt activation. Br J Cancer 109: 1586-1592, 2013.

35. Weigelt B, Warne PH and Downward J: PIK3CA mutation, but not PTEN loss of function, determines the sensitivity of breast cancer cells to mTOR inhibitory drugs. Oncogene 30: 3222-3233, 2011.

36. Chaft JE, Arcila ME, Paik PK, Lau C, Riely GJ, Pietanza MC, Zakowski MF, Rusch V, Sima CS, Ladanyi M and Kris MG: Coexistence of PIK3CA and other oncogene mutations in lung adenocarcinoma-rationale for comprehensive mutation profiling. Mol Cancer Ther 11: 485-491, 2012.

37. Janku F, Wheler JJ, Westin SN, Moulder SL, Naing A, Tsimberidou AM, Fu S, Falchook GS, Hong DS, Garrido-Laguna I, et al: PI3K/AKT/mTOR inhibitors in patients with breast and gynecologic malignancies harboring PIK3CA mutations. J Clin Oncol 30: 777-782, 2012.

38. De Roock W, Claes B, Bernasconi D, De Schutter J, Biesmans B, Fountzilas G, Kalogeras KT, Kotoula V, Papamichael D, Laurent-Puig P, et al: Effects of KRAS, BRAF, NRAS, and PIK3CA mutations on the efficacy of cetuximab plus chemotherapy in chemotherapy-refractory metastatic colorectal cancer: A retrospective consortium analysis. Lancet Oncol 11: 753-762, 2010.

39. Park JH, Ryu MH, Park YS, Park SR, Na YS, Rhoo BY and Kang YK: Successful control of heavily pretreated metastatic gastric cancer with the mTOR inhibitor everolimus (RAD001) in a patient with PIK3CA mutation and $\mathrm{pS} 6$ overexpression. BMC Cancer 15: 119, 2015. 